\title{
A Strategic Model Of European Gas Supply
}

Vitaly Kalashnikov, Durango State University, Mexico

Nataliya Kalashnykova, University of Neuvo Leon, Mexico

\begin{abstract}
Structural changes in the European natural gas market such as liberalization, increasing domestic demand, and increasing import dependency have triggered new attempts to model these markets accurately. In this paper, we propose an exhaustive model of the European natural gas supply including the possibility of strategic behaviour of the agents along the value-added chain. We structure it as a two-stage-game with natural gas exports to Europe (first stage) and wholesale trade within Europe (second stage). The case of non-cooperative Cournot competition at both stages proves to be the most realistic scenario. The results of the perfect competition and cartel scenario are also presented. Our results suggest that the main suppliers of natural gas to Europe (Russia, Algeria, the Netherlands, Norway) remain dominant, but that they are complemented by overseas supplies of liquefied natural gas (LNG). The model also enables us to identify transport infrastructure bottlenecks where transport capacity constraints are binding.
\end{abstract}

Keywords: natural gas, strategic behaviour, non-linear optimization

\section{INTRODUCTION}

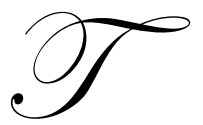

he European gas market has a number of a various aspects: from the definition of the most suitable economic behaviour to the market liberalization which aims to boost competition at the level of each member state as well as within the European Union (EU), to the decrease in the dependency on certain non-EU suppliers, which should increase the competition among the non-EU exporters. Therefore, observing the strategic behaviour of the market players (e.g. related to net access, cooperation or refusal to collaborate, etc.) becomes crucial.

There are different mathematical models for describing the behaviour of a competitive market. For the scope of this paper, the EU natural gas market is modelled using a game theoretic model. The authors compare the strategic behaviour of the market players reflected by their market influences based on the Nash equilibrium theory among an environment of perfect competition.

In the case of perfect competition, each agent acts as a price taker, equalizing prices and marginal costs in order to optimise profit. The paper further considers the Cournot model, at the Nash equilibrium, where electricity firms aim to maximize their profit and enlarge their market shares taking into consideration various relationships between the real market elasticity values and assumptions about the behaviour of other players. The results of the cartel model are also presented.

The model follows a number of other modelling attempts of the European gas sector. The structure of the sector suggests modelling the market with oligopolistic competition in a game theoretic framework. Most models actually distinguish the upstream market among producers (gas extraction/production taking place mostly outside Europe) and the downstream trader market (i.e. the wholesale market inside Europe).

Golombek et al. (1995) were the first of the recent literature to study the effects of liberalizing the natural gas market in Western Europe. They distinguish between upstream (producers) and downstream (traders) agents on the gas market. Here, liberalization of the European gas market is defined as the situation where downstream traders can exploit arbitrage possibilities between countries as well as between market segments (industry, and local distribution companies for households). Their numerical model yields that liberalization increases upstream 
competition. In an extension of this model, Golombek et al. (1998) study the supply side and the optimal number of producers. They assume a liberalized demand side, that is producers sell directly to end-consumers in an integrated.

The EUGAS model (Perner and Seeliger (2004)) analyses the long-term gas supply to Europe. It is a model of linear optimization of European gas supply taking into account production and transport capacities, but treating gas demand exogenously. The most interesting feature of the model is the explicit recognition of infrastructure capacities (pipelines and LNG terminals) The EUGAS model has recently been extended by introducing global gas reserves, without however modifying the linear optimization structure (Düweke and Hamacher (2005)).

The GASTALE model (Boots et al. (2004)) is the first model to use the structure of successive oligopoly in gas production and trading. This model is similar to ours in that its underlying structure is a two-stage game.

Hirschhausen et al. (2005) consider the options for Russia to transport its gas to Western Europe. Here, the players Russia and Ukraine could either play a cooperative or a non-cooperative game. The analytical results as well as numerical simulation results show that the construction of pipelines through Belarus results in higher profits for Russia while Ukraine loses.

Given the growing scope of the European natural gas market, and the need for a policy relevant analysis, the scope of the existing models with regard to demand and supply structures, and in particular the infrastructure component, remains unsatisfying. The model developed in this paper, aims at combining a realistic representation of the market structure with a dynamic infrastructure analysis. Moreover we improve the data and use more detailed data than in previous models of the European gas sector. The remainder of the paper is structured as followed. In Section 2, we will outline the structure of the European gas market, with an emphasis on the natural gas trade. In Section 3, we will give a detailed description of the model and the used data. The subsequent presentation in Section 4 of the main simulation results will be followed by the conclusions (Section 5).

\section{STRUCTURE OF THE EUROPEAN GAS SECTOR}

We have stated that the European gas market currently faces three main challenges. There are changes ongoing on the demand side as well as on the supply side and the speed of reforms is accelerating. These changes do not only have an impact on the natural gas market within Europe but also on the supply relations of Europe with other gas producing countries. Hence, the gas sector has been identified as a strategic sector by the European Commission (European Commission (2001)) and by the International Energy Agency (IEA).

First, European demand of natural gas is highly likely to increase further over the next decades. The share of natural gas in total primary energy demand in the European Union (EU-25) is expected to increase from 23\% at present to a projected $32 \%$ in 2020 . There will also be an increase in the absolute level of gas consumption from approximately 390 Mtoe per year today to a projected 565 Mtoe per year in 2020 (IEA (2004d)). The demand increase will mainly be driven by an increasing utilization for power generation.

Second, since Europe can only partly satisfy its gas demand with indigenous production, rising demand also means an increasing import dependency. Indigenous production in Europe is concentrated in the UK, the Netherlands and Norway. However, production in these countries will at best remain at the current level but will probably decrease because the fields in the North Sea are running out of gas. So, in different scenarios, the gas import dependency of the EU-25 is estimated by the International Energy Agency to increase from the current $49 \%$ (233 bcm in 2002) to over $80 \%$ (639 bcm) in 2020.

At present, it is unclear where the additional gas will come from. Russia currently is the most important gas supplying country to the European Union and is expected to expand this role with a market share usually projected to increase from the current $40 \%$ of EU imports to two-thirds. Additional gas supplies will also have to come from new areas such as the Middle East, where Liquefied Natural Gas (LNG) is a form of supply of growing importance.

Third, the European Commission has pushed for a progressive liberalization of the European natural gas 
sector, a process which is still ongoing. Liberalization of the EU wholesale market and of gas distribution has led to a partial abandon of long-term contracts in the supply relationships. Previous liberalization experiences in the US and the UK have shown that the share of long-term contracts diminishes, although it always remains (well) above $50 \%$. So, LNG but also pipeline transported gas from "new" suppliers (Middle East etc.) could be beneficiaries of market liberalization in the EU. Traders in the EU are thus enabled to diversify their sources of supply.

\section{MODEL DESCRIPTION AND DATA}

\subsection{Model}

In this paper we examine the case when, at the starting and the finishing stages of the game, natural gas suppliers realize a Cournot-Nash equilibrium with their profits maximized. Profits are calculated upon marginal production costs and price dependent demand, the latter relationship being represented by an inverse demand function, which is twice continuously differentiable.

As a comparison we also include the perfect market scenario, where all the market agents act simply as price takers, and also the cartel situation for the natural gas exporters to Europe (we do not consider the cartel among the intra-European traders).

At the intermediate stage of the game, firms maximize their profits given the strategic behavior of the other agents. Profits are computed on the base of variable production costs, maximum net power, net access costs and transportation costs. Market shares which may change with merges or cooperation also play an important role. In the oligopolistic market structure, prices can be dependent upon the market shares and market powers. Prices are also influenced by the price elasticity of demand, and it is exactly there that the influence coefficients arise.

In a situation of perfect competition, that is not the case. When solving optimization problems it is often useful to remember that each such a problem can be reduced to a complementarity problem. Generally speaking, in the complementarity framework, either a nonnegative variable is zero, or the corresponding inequality constraint is active, i.e. it is in fact an equality. Primarily, by solving a mixed complementarity problem (MCP), the KarushKuhn-Tucker (KKT) optimality conditions are determined and solved for a decision variable. The MCP format and the KKT conditions are equivalent. Therefore, each MCP can be transformed to the classical optimality conditions and vice versa. The idea behind the MCP formulation is to develop a program that permits the classical decomposition method to be obsolete, instead ascertaining the MCP conditions directly. The main advantages of MCP are: (1) the simultaneous and parallel determination of decision variables and side constraints, and (2) the solution of complex mathematical programs without an explicit formulation of the objective function. Specially developed solvers detect the MCP format directly and point out, if necessary, if side constraints are defined incorrectly. Present day computer technologies allow an uncomplicated and fast solution of MCPs by mathematical algorithms. At this moment, for instance, GAMS provides MILES and PATH as major solvers. In addition, applying the MCP method one avoids the intricacy of finding a solution by a standard nonlinear programming (NLP) solver when the starting values are distant from the optimum point. Transforming an optimization problem into a MCP formulation requires a specification of the first order optimality conditions taking into account all the upper and lower bounds of the decision variables.

Notation:

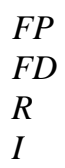

$F D$

$I$
- collection of firms-providers

- collection of firms-distributors

- list of European importing countries

- set of sources (domestic (d) or import (i)) 
Parameters

$\begin{array}{ll}c(i, r) & \text { - unit production cost } \quad i \in I, r \in R \\ \operatorname{deO}(r) & \text { - reference demand for gas in region } r \\ \operatorname{peO}(r) & \text { - reference price of gas in region } r \\ \sigma_{r} & \text { regional price elasticity }\end{array}$

Variables

$s(f, r)$

$p e 2(r)$ $p e(r)$
- supply by firm $f$ to region $r, f \in\{F P, F D\}, r \in R$;

- provider's price of gas in region $r$

- distributor's price of gas in region $r$

We assume the (long-run) demand elasticity values to be rather low ( -0.8 for Western Europe, -0.7 for the Eastern Europe), which reflects certain inelasticity of the natural gas demand: shifting from gas to another fuel would require changes in the technical installations which are costly and time consuming.

Each player is restricted by capacity limitations such as transport infrastructure constraints (export, import capacities in terms of pipelines and LNG terminals), production capacities. On the first stage of exports to Europe, gas trade is restricted by the export infrastructure of each producer and the import capacity of each wholesale trader. On the second stage, the supply by each trader is restricted by his domestic production capacity as well as by his earlier import capacity; his re-sales are limited to the capacity of the pipeline grid between him and each end-user market.

On both stages, each player maximizes his profit under certain capacities constrains:

\section{- $\quad$ Stage 1:}

Each exporter maximizes its profit, given its unit costs of production and transport to the particular country $r$, its total export/transport capacity, the import capacity of the customer, the reference demand (deO) and price elasticity $(\sigma)$ in each importing country.

$$
\Pi(f)=\sum_{r} p e(r) s(f, r)-\sum_{r} c(f, r) s(f, r) \rightarrow \max
$$

which is subject to infrastructure capacities constraints and the market clearing constraints:

$$
\sum_{f \in F P} s(f, r)=\operatorname{de} 0(r)\left(\frac{p e(r)}{p e 0(r)}\right)^{\sigma_{r}}, r \in R
$$

\section{- $\quad$ Stage 2:}

Each European gas trading company maximizes its profit, analogously to as in the previous stage, given its unit production costs ( composed of costs of importing and costs of indigenous production), transport capacities, the reference demand $(d e O)$ and price elasticity $(\sigma)$ in each importing country.

$$
\Pi(f)=\sum_{r} p e 2(r) s(f, r)-\sum_{r} c(d, r) s_{d}(f, r)-\sum_{r} c(i, r) s_{i}(f, r) \rightarrow \max
$$

which is subject to inner-European capacities constraints and market clearing condition inside of Europe: 
where

$$
\begin{gathered}
s(f, r)=s_{d}(f, r)+s_{j}(f, r), f \in F D, r \in R \\
\sum_{f \in F D} s(f, r)=d e 0(r)\left(\frac{p e 2(r)}{p e 0(r)}\right)^{\sigma_{r}}, r \in R
\end{gathered}
$$

with $s_{d}(f, r)$ and $s_{i}(f, r)$ denoting the domestic and imported supply, respectively, by firm $f$.

In the framework of the model, we check for the total balancing: $\quad \sum_{r \in R} \sum_{f \in F D} s_{i}(f, r)=\sum_{r \in R} \sum_{f \in F P} s(f, r)$.

The profit maximization problem of each individual player (producer or trader) is solved as a mixed complementarity problem (MCP) which is programmed in GAMS. The MCP format is non-linear optimization program that simultaneously takes into account all side constrains, which in our model are the production and capacity constraints.

\subsection{Data}

We aim at having an exhaustive representation of all relevant players on the European natural gas market. In Table 1, we summarize the included exporting and importing regions. We include Egypt, Iraq and Venezuela and aggregated supplier "Others" although they have no gas export capacity to Europe, in order to balance the European natural gas market with the global gas market. The aggregated market importer is presented as "rest of the world" having the same proposal. We assume that there is one gas company per country or region, which is justified by the existence of national (quasi-) monopolies in reality, such as GdF in France, Gasprom in Russia, etc.

$\begin{array}{cc}\text { Exporting Regions } & \text { Importing Regions } \\ \text { Algeria } & \text { United Kingdom } \\ \text { Libya } & \text { Netherlands } \\ \text { Egypt } & \text { Spain / Portugal } \\ \text { Iraq } & \text { France } \\ \text { Iran } & \text { Italy / Switzerland } \\ \text { Middle East (Qatar, UAE, Oman) } & \text { Belgium / Luxemburg } \\ \text { Former Soviet Union } & \text { Germany } \\ \text { Norway } & \text { Denmark } \\ \text { Netherlands } & \text { Sweden / Finland } \\ \text { United Kingdom } & \text { Austria } \\ \text { Nigeria } & \text { Poland } \\ \text { Trinidad } & \text { Czech Rep. / Slovak Rep. / } \\ \text { Venezuela } & \text { Hungary } \\ \text { Others } & \text { Former Yugoslavia / Albania } \\ & \text { Romania / Bulgaria } \\ & \text { Baltic States (Estonia, Latvia, } \\ & \text { Lithuania) } \\ & \text { Greece } \\ & \text { Turkey } \\ & \text { RoW (rest of the world) }\end{array}$

Table 1: Regions in the model

We use the data for the base year 2003. Data on reference trade flows and prices come from the International Energy Agency (IEA 2004a, 2004b) and from BP (2004). Data on production capacity in the European regions is from IEA (2004b). Transport capacity data mainly come from GTE the European organization of the national TSOs (transmission system operators) for intra-European capacities, and from OME (2001) for exporter capacities. 
We use this data not only for availability reasons but also because the equilibrium results have to be situated in a long-run perspective.

The cost data is a crucial input to the model with an important influence on the results. In the OME (2001) data, LNG is still a high-cost supplier with costs of around 3 US-\$ per Mbtu for typical LNG exporters as Nigeria, Venezuela and the Middle East.

Norway is a producer at fairly high costs, whereas Algeria and to a less extent Russia can export at relatively low costs to Europe (OME (2001), pp. 18). Political and other "soft" considerations (e.g. the reliability of an exporter) do not enter the cost data and consequently not the model. The same is true for reserves which do not enter in the production capacity of the producers.

\section{SIMULATION RESULTS}

The model is run for three different scenarios. They are: the perfect competition, Cournot-Nash scenario and the cartel for Stage 1 market agents.

\subsection{First Stage: Exports To Europe}

The distribution of profits (Table 2) clearly shows that not only the profits are higher in the oligopolistic scenario, as expected, but there are also more players earning profits. The cartel scenario only enhances those effects, but has a devastation impact on the domestic European prices, as will be shown in the next session.

\begin{tabular}{|l|c|c|c|c|c|c|c|}
\hline Exporters & $\underline{\text { Algeria }}$ & Libya & $\underline{\text { Egypt }}$ & $\underline{\text { Iraq }}$ & $\underline{\text { Iran }}$ & Middle East & $\underline{\text { FSU }}$ \\
\hline Competition & 2,829 & 0,094 & & & 0,211 & 0,001 & 6,939 \\
\hline Cournot & 3,420 & 0,167 & & & 0,389 & 0,494 & 7,346 \\
\hline Cartel & 3,980 & 0,211 & & & 0,415 & 0,615 & 8,694 \\
\hline Exporters & $\underline{\text { Norway }}$ & $\underline{\text { Holland }}$ & $\underline{\text { UK }}$ & $\underline{\text { Nigeria }}$ & $\underline{\text { Trinidad }}$ & & \\
\hline Competition & 1,289 & 0,498 & 0,794 & 0,0 & 0,0 & & \\
\hline Cournot & 1,587 & 0,697 & 1,111 & 0,216 & 0,12 & & \\
\hline Cartel & 1,794 & 0,897 & 1,254 & 0,3 & 0,15 & & \\
\hline
\end{tabular}

Table 2: Profits of the exporters to the EU in the Perfect Competition and Cournot scenarios in billion USD.

\subsection{Second Stage: Intra-European Trade}

The second stage of the model performs the re-sales of the imported gas by wholesale traders, together with domestically produced natural gas. Under our assumption of liberalized access to the transportation networks and distribution in Europe, there is indeed a vital wholesale trade between European countries, with e.g. Germany exporting $7.2 \mathrm{bcm} /$ year to France, or France exporting $7.1 \mathrm{bcm} /$ year to Italy/Switzerland. Thus, although the players on the market are behaving strategically, free market access can assure international trade.

But many wholesale trade flows are subject to binding infrastructure reflecting that at present there are only limited infrastructure capacities between European countries. Especially the border between Spain and France, and the connection to the United Kingdom are transport bottlenecks. The same is true for many Eastern European regions (Romania/Bulgaria, the Baltic States, also Greece) which have no or only limited access to the European wholesale market. This can be an explanation why these regions have higher prices.

\subsection{Prices On The Upstream And Downstream Market}

As it can be easily seen, the classical Nash equilibrium can be taken as the most plausible intermediate model between the perfect competition scenario and the situation, when the exporters form the gas-cartel (like the 
OPEC). Even though, the difference between the perfect competition and the oligopolistic markets shows not to be too remarkable due to the large number of natural gas exporters to the Europe, as well as the large number of interEuropean market agents, which seems to ensure an acceptable level of competition. The cartel scenario, in contrary, leads to up to 1.5 times increment of the domestic prices for the European customers.

$\begin{array}{lccc}\text { Markets } & \text { Competition } & \begin{array}{c}\text { 2nd stage: European market } \\ \text { Cournot }\end{array} & \text { Cartel } \\ \text { UK } & 114,18 & 133,05 & 189,21 \\ \text { Netherlands } & 111,44 & 134,00 & 189,14 \\ \text { Spain/Portugal } & 123,15 & 136,12 & 189,34 \\ \text { France } & 116,08 & 134,36 & 189,19 \\ \text { Italy/Switzerland } & 119,55 & 134,27 & 189,25 \\ \text { Belgium/Lux } & 117,28 & 134,89 & 189,11 \\ \text { Germany } & 117,11 & 132,21 & 189,00 \\ & & & 189,03 \\ \text { Denmark } & 118,15 & 133,77 & 191,34 \\ \text { Sweden/Finland } & 119,89 & 134,09 & 189,01 \\ \text { Austria } & 118,24 & 135,26 & 188,34 \\ \text { Poland } & 121,88 & 134,59 & 189,28 \\ \text { Czech/Slovak Rep./Hungary } & 122,10 & 133,713 & 190,17 \\ \text { Balkan } & 124,08 & 135,29 & 189,99 \\ \text { Romania/Bulgaria } & 125,11 & 135,33 & 189,56 \\ \text { Baltic } & 124,87 & 135,11 & 189,02 \\ \text { Greece } & 119,43 & 133,82 & 189,46 \\ \text { Turkey } & 122,64 & 134,37 & \end{array}$

Table3: Simulation results: prices in USD per thousand cubic meters.

\section{CONCLUSIONS AND OUTLOOK}

We have presented a quasi-static model of the European natural gas market. We focus on the modelling of the situation of double marginalization that can actually be observed in reality. Exporters to Europe as well as wholesale trading firms in Europe are a small number and behave strategically. Hence, our model can be of particular interest to policy advice because it explains a situation of imperfect competition in a liberalized natural gas market. We explicitly take into account infrastructure capacities which may be binding, while solving a nonlinear optimization.

Our results suggest that the main suppliers of natural gas to Europe (Russia, Algeria, the Netherlands, Norway) remain dominant, but that they will be complemented by overseas supplies of LNG. The higher price in Cournot competition allows market entry of higher cost exporters (mostly LNG producers from the Middle East, Nigeria and the Caribbean) while total gas demand in Europe is lower, thereby crowding out some traditional supplies. We identify infrastructure bottlenecks for a number of low cost producers such as Algeria, the Netherlands, the UK. However, we are aware that this result depends crucially on the cost data that enters the model.

Consequently, there are several improvements which should be included in the model. Cost data needs to be more reliable, especially for LNG, and one usage of a cost function instead of point cost data should be considered. In addition, temporal distortions which might enter the model by using data for one single base year (2003) could be removed. Also, capacity and transport cost data needs improvement since some data points rely on our own assumptions. The same holds for demand elasticity values. 


\section{ACKNOWLEDGEMENTS}

The second author' research activity was financially supported by the CONACyT (Mexico) project SEP2004-C01-45786. The first author's work was supported by the Academic Program (Cuerpo Académico) of the Civil Engineering and Architecture Department (FICA) of the Durango State University named after Juárez (UJED) Gómez Palacio, Durango, Mexico.

\section{REFERENCES}

1. Boots, Maroeska G., Fieke A.M. Rijkers and Benjamin F. Hobbs, 2004: Trading in the Downstream European Gas Market: A Successive Oligopoly Approach. Energy Journal, Vol. 25, No. 3, pp. 73-102.

2. BP, 2004: Energy in Focus - BP Statistical Review of World Energy June 2004. British Petroleum.

3. Commission, European, 2001: Green Paper - Towards a European strategy for the security of energy supply. European Commission, DG TREN: Brussels.

4. Düweke, Jörg and Thomas Hamacher, 2005: Modellierung der globalen Ergasressourcen und des Erdgastransports. presented at IEWT 2005: Vienna (Austria).

5. Golombek, Rolf, Eystein Gjelsvik and Knut Einar Rosendahl, 1995: Effects of Liberalizing the Natural Gas Markets in Western Europe. Energy Journal, Vol. 16: 85-111.

6. Golombek, Rolf, Eystein Gjelsvik and Knut Einar Rosendahl, 1998: Increased Competition on the Supply Side of the Western European Natural Gas Market. Energy Journal, Vol. 19, No. 3, pp. 1-18.

7. Grais, Wafik and Kangbin Zheng, 1996: Strategic Interdependence in European East-West Gas Trade: A Hierarchical Stackelberg Game Approach. Energy Journal, Vol. 17, No. 3, pp. 61-84.

8. Hartley, Peter and Kenneth B. Medlock, 2004: A Global Market for Natural Gas? Prospects to 2035. Geopolitics of Gas Working Paper Series: 1-19: Stanford (Ca., USA).

9. Hirschhausen, Christian von, Berit Meinhart and Ferdinand Pavel, 2005: Transporting Russian Gas to Western Europe - A Simulation Analysis. Energy Journal, Vol. 26, No. 2.

10. IEA, 2004a: Energy Prices and Taxes - Quarterly Statistics - Third Quarter 2004. International Energy Agency: Paris.

11. IEA, 2004b: Natural Gas Information. International Energy Agency: Paris.

12. IEA, 2004c: Security of Gas Supply in Open Markets - LNG and Power at a Turning Point. Paris, OECD.

13. IEA, 2004d: World Energy Outlook 2004. Paris, OECD/IEA.

14. Knieps, Günter, 2001: Wettbewerbsökonomie - Regulierungstheorie, Industrieökonomie, Wettbewerbspolitik. Berlin u.a., Springer.

15. OME, 2001: Assessment of internal and external gas supply options for the EU - Evaluation of the supply costs of new natural gas supply projects tot he EU and an investigation of related financial requirements and tools. Observatoire Méditerranéen de l'Energie.

16. Perner, Jens and Andreas Seeliger, 2004: Prospects of gas supplies to the European market until 2030results from the simulation model EUGAS. Utilities Policy, Vol. 12, No. 4, pp. 291-302. 